\title{
Thymic Function and Impaired Maintenance of Peripheral T Cell Populations in Children with Congenital Heart Disease and Surgical Thymectomy
}

\author{
NANCY J. HALNON, BETH JAMIESON, MARK PLUNKETT, CHRISTINE M.R. KITCHEN, \\ THAO PHAM, AND PAUL KROGSTAD \\ Department of Pediatrics [NJ.H., T.P., P.K.], Department of Medicine [B.J.], Department of Surgery \\ [M.P.], and Department of Molecular and Medical Pharmacology [P.K.], David Geffen School of \\ Medicine at the University of California, Los Angeles, Los Angeles, California, 90095, and UCLA School \\ of Public Health [C.M.R.K.], Los Angeles, California, 90095
}

\begin{abstract}
The thymus begins involution in childhood and historically it was thought to be nonfunctional by adulthood, thus presenting no contraindication to the routine practice of thymectomy during cardiothoracic surgery. More recent data suggest, however, that the thymus remains active into adulthood and is responsible for the low-level production of normal $\mathrm{T}$ cells. We hypothesize, therefore, that incidental thymectomy during cardiothoracic surgery in infancy causes long-term changes in the cellular immune system. To investigate this hypothesis, we quantified peripheral T-cell subsets and T-cell recombination excision circles in children with congenital heart disease to measure the impact of cardiothoracic surgical procedures and thymectomy performed
\end{abstract}

ABSTRACT

during a period of immunologic development. We found that cardiothoracic surgical procedures, especially if they include thymectomy, impair T-cell production and produce long-term decreases in total lymphocyte count and $\mathrm{CD} 4^{+}$and $\mathrm{CD} 8^{+} \mathrm{T}$-cell subsets, suggesting that long-term maintenance of lymphocyte populations is disturbed. (Pediatr Res 57: 42-48, 2005)
MG, myasthenia gravis
Abbreviations
PBMC, peripheral blood mononuclear cells
RTE, recent thymic emigrants
TREC, T cell receptor recombination excision circles

Children undergoing corrective or palliative cardiothoracic surgeries frequently undergo incidental thymectomy to increase exposure of the surgical field. Although profound immune deficiency is known to result from the absence of a thymus during fetal development (1-3), little is known of the effects of thymectomy in humans during a period of postnatal immunologic development. Short-term studies to date have not documented overt immune deficiency in infants who have been subjected to incidental thymectomy during cardiothoracic sur-

Received June 14, 2004; accepted September 2, 2004.

Correspondence: Paul Krogstad, M.D., Division of Pediatric Infectious Diseases, Mattel Children's Hospital at UCLA, MDCC 22-442, 10833 LeConte Ave., Los Angeles, CA 90095; e-mail: pkrogstad@mednet.ucla.edu

Supported by a Research Fellowship Award from the American Academy of Pediatrics to N.H. and the Laubisch Foundation. The authors would like to acknowledge Mr. Gerald Oppenheim for a seed grant that supported this research. P.K. is an Elizabeth Glaser Scientist of the Pediatric AIDS Foundation. Flow cytometry was performed in the UCLA Jonsson Comprehensive Cancer Center and Center for AIDS Research Flow Cytometry Core Facility that is supported by National Institutes of Health awards CA-16042 and AI-28697, by the Jonsson Cancer Center, the UCLA AIDS Institute, and the UCLA School of Medicine.

DOI: 10.1203/01.PDR.0000147735.19342.DE gery (4-7). However, until recently, it has been difficult to quantify activity of the thymus, even in normal individuals, making it difficult to assess the impact of thymectomy on the naïve T-cell compartment and on de novo $\mathrm{T}$-cell production and the subsequent effects on adaptive immunity.

Initial attempts to quantify the contribution of thymopoiesis to the cellular immune system during postnatal development and into adulthood have focused on the phenotypic measurement of the naïve T-cell population in peripheral blood. These cells, by definition, are mature, circulating T cells that have not yet encountered their cognate antigens. Naïve $\mathrm{T}$ cells were initially identified as $\mathrm{CD}^{+}$or $\mathrm{CD}^{+}$cells that also express CD45RA on their surface. Use of multiple-color flow cytometry has brought into question the reliance on CD45RA expression alone, as up to $10-30 \%$ of $\mathrm{CD}^{+}{ }^{+}$or $\mathrm{CD}^{+} \mathrm{CD}^{+} 5 \mathrm{RA}^{+}$ $\mathrm{T}$ cells lack cell-surface markers and cytokine expression profiles characteristic of naïve cells (8). Flow cytometric markers also fail to differentiate RTE from naïve $\mathrm{T}$ cells produced by clonal expansion in the periphery. However, Douek et al. $(9,10)$ developed a PCR-based assay that permits quantification of cells bearing TREC, which are nonreplicating circular DNA 
molecules generated during excisional rearrangement of the coding sequences for T-cell receptor proteins. TREC remain in $\mathrm{T}$ cells after their maturation and release from the thymus to the periphery. Although they are diluted as cells proliferate, the number of TREC serves as a parameter of thymopoiesis (1113). The use of these techniques has demonstrated that the thymus normally remains active well into adulthood, and that its function is required for reconstitution of immune function during treatment for HIV infection, and after cytolytic cancer chemotherapy or bone marrow transplantation $(10,14-18)$.

To investigate the long-term effects of thymectomy during immune development in young children, we have examined thymic function and peripheral T-cell populations in children between 2 mo and $17 \mathrm{y}$ after surgery for repair or palliation of congenital cardiac lesions. We evaluated the long-term consequences of incidental thymectomy in infancy in a cohort of subjects with congenital heart disease who have undergone corrective or palliative surgical procedures early in life, comparing subjects with complete thymectomy with those without prior surgery, and those whose thymus was spared during surgery.

\section{METHODS}

Selection of study subjects. Subjects with a history of congenital heart disease presenting for evaluation before an initial or repeat cardiothoracic surgical procedure were recruited for study. Sixty-nine individuals ranging from $1 \mathrm{mo}$ to $18 \mathrm{y}$ in age were enrolled after informed consent was obtained according to a protocol reviewed and approved by the UCLA Medical Institutional Review Board. Medical history was obtained, including age, specific congenital cardiac diagnosis, recent and past infectious illnesses, and history of prior surgical procedures. To eliminate the confounding effects severe physical debilitation might have on immune function, subjects were recruited only from those well enough to await elective surgical procedures. The subjects with asthma (two individuals) and one subject with a history of cardiac transplantation had no history of recent steroid use.

Subjects were excluded if they had a history of 22q11 chromosomal deletion (by fluorescence in situ hybridization) or recent infections. Subjects, who after evaluation did not undergo a surgical procedure or for whom intraoperative visualization of midline structures did not occur (e.g. if the surgical approach was not via median sternotomy), were also excluded. Analysis was then performed on 55 individuals.

Intraoperative assessment of thymus remaining after a prior surgical procedure. The surgeon or an assistant present during opening of the chest during the surgical procedure provided a visual assessment of thymic tissue present in the anterior mediastinum at the start of the current surgical procedure. The observer graded thymic tissue as present if any recognizable thymic tissue was present regardless of gross appearance or absent if no recognizable thymic tissue was present. Two subjects whose observer reported the presence of only "trace" thymus tissue were included in the "residual thymus present" group. Pathologic analysis was performed on tissue from subjects who underwent thymectomy. Thymic tissue was reported to be normal by histologic evaluation in all those in whom examination was performed. A history of at least partial thymectomy was documented in 8 of 18 subjects in whom residual thymus was present. Of the 11 subjects with no residual thymus, all except 2 (for whom previous records were unavailable) had documented removal of histologically normal thymus tissue at a previous surgery. MRI available for four subjects was used to confirm the accuracy of visual assessment.

Cell isolation. Peripheral blood samples from subjects undergoing cardiothoracic surgery or laboratory evaluation were collected into EDTA tubes, and separation of PBMC was performed by Ficoll-Hypaque density gradient centrifugation. Each sample was processed within $24 \mathrm{~h}$ of collection. PBMC were viably stored in liquid nitrogen for flow cytometry and at $-20^{\circ} \mathrm{C}$ for TREC analysis.
Quantitation of TREC and cellular DNA. DNA was extracted from PBMC using $100 \mu \mathrm{g} / \mathrm{mL}$ proteinase K (Boehringer Ingelheim, Ridgefield, CT) diluted in $10 \mathrm{mM}$ Tris and $0.5 \mathrm{mM}$ EDTA. Samples were incubated for $1 \mathrm{~h}$ at $56^{\circ} \mathrm{C}$ and then for 10 min at $95^{\circ} \mathrm{C}$. TREC were quantified using real-time PCR analysis, using the 5' nuclease (TaqMan) assay and the ABI Prism 7700 sequence detector system (Applied Biosystems, Foster City, CA) as previously described (19). A $25-\mu \mathrm{L}$ PCR mixture consisted of $5 \mu \mathrm{L}$ of genomic DNA extract, $1 \times$ PCR buffer containing $20 \mathrm{mM}$ Tris and $50 \mathrm{mM} \mathrm{KCl}, 3.5 \mathrm{mM} \mathrm{MgCl}_{2}, 1 \mu \mathrm{L} 5$ $\mathrm{mM}$ dNTP, $1 \mu \mathrm{L} 12.5 \mathrm{pM}$ forward primer (CACATCCCTTTCAACCATGCT), $1 \mu \mathrm{L} 12.5 \mathrm{pM}$ reverse primer (GCCAGCTGCAGGGTTTAGG), $1 \mu \mathrm{L}$ $5 \mu \mathrm{M}$ probe (FAM-5'ACACCTCTGGTTTTTGTAAAGGTGCCACT-3'TAMRA) (MegaBases, Chicago, IL), $0.25 \mu \mathrm{L} 10 \mu \mathrm{M}$ BD 636 reference dye (MegaBases), and $0.125 \mu \mathrm{L}$ platinum Taq polymerase. The PCR conditions were set at $95^{\circ} \mathrm{C}$ for $5 \mathrm{~min}, 95^{\circ} \mathrm{C}$ for $30 \mathrm{~s}$, and $60^{\circ} \mathrm{C}$ for $1 \mathrm{~min}$ for 40 cycles. A standard curve for TREC copy number was established with a range of 25 to $10^{6}$ copies of plasmid containing signal joint TREC (kindly provided by D. Doueck) (10). All samples were analyzed in triplicate using a single lot of serially diluted plasmid as standards for all assays. The mean of the triplicate TREC values was used for data analysis. As previously described, the coefficient of variation among replicates was less than $20 \%$ for nearly all samples (19).

The number of cells in each test sample was confirmed using real-time PCR to amplify CCR5 DNA sequences using a primer-probe combination supplied by D. Douek. A $25-\mu \mathrm{L}$ PCR mixture consisted of $5 \mu \mathrm{L}$ of genomic DNA extract, $1 \times$ PCR buffer containing $20 \mathrm{mM}$ Tris and $50 \mathrm{mM} \mathrm{KCl}, 3.5 \mathrm{mM}$ $\mathrm{MgCl}_{2}, 1 \mu \mathrm{L} 5 \mathrm{mM}$ dNTP, $1 \mu \mathrm{L} 12.5 \mathrm{pM}$ forward primer (TACCTGCTCAACCTGGCCAT), $1 \mu \mathrm{L} 12.5 \mathrm{pM}$ reverse primer (TTCCAAAGTCCCACTGGGC), $1 \mu \mathrm{L} 5 \mu \mathrm{M}$ probe (5'FAM-TTTCCTTCTTACTGTCCCCTTCTGGGCTC-TAMRA3'), $0.25 \mu \mathrm{L} 10 \mu \mathrm{M}$ Blue 636 reference dye, and $0.125 \mu \mathrm{L}$ platinum Taq polymerase using PCR conditions as described for TREC analysis. We used an estimate of $8 \mu \mathrm{g}$ of DNA per million PBMC. Results were expressed as TREC $/ 10^{6}$ cells. Using a standard curve with a range of 25 to $10^{6} \mathrm{TREC} / \mathrm{sample}$, the assay has a limit of detection of approximately 400-3000 TREC/million PBMC depending on the number of cells analyzed. For samples with undetectable TREC levels, values were recorded at the limit of detection for the individual sample.

Cell staining and flow cytometry. Whole-blood cell staining was done to determine the percentages of $\mathrm{CD}^{+} \mathrm{CD}^{+}, \mathrm{CD}^{+} \mathrm{CD}^{+}$, and $\mathrm{CD} 4^{+}$

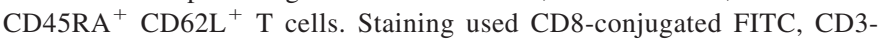
conjugated phycoerythrin (PE), CD4-conjugated allophycocyanin (APC), or peridinin chlorophyll protein (PerCP), CD45RA-conjugated FITC, and CD62L-conjugated PE antibodies (BD Biosciences, San Diego, CA) according to the manufacturer's instructions. Cells were acquired on a FACSCalibur flow cytometer and the data were analyzed using CellQuest Software (BD Biosciences). For selected subjects cryopreserved PBMC were reanalyzed to quantify cells with simultaneous expression of $\mathrm{CD} 4^{+}, \mathrm{CD} 27^{+}$, and CD45RA ${ }^{+}$ (naive helper $\mathrm{T}$ cell). For all of the above-mentioned T-cell subsets, associations were analyzed for both percentages of each cell type as well as absolute cell counts; both were used as continuous variables.

Statistical analysis. Based on intraoperative assessment, subjects were grouped as follows: no previous surgery, previous surgery—no residual thymus, or previous surgery-residual thymus present. TREC values were normalized using the square root transformation. Data were analyzed using mixed effects regression. Median group differences were analyzed using the KruskalWallis test. Individual differences between groups were analyzed using the Wilcoxon rank-sum test.

\section{RESULTS}

To examine consequences of thymectomy in young children, we examined T-cell subsets and parameters of thymopoiesis in children and young adults presenting for cardiothoracic surgical procedures. Results obtained from these subjects were compared with data obtained from a group of children with congenital heart disease examined before any surgical intervention. All subjects were clinically well at the time of evaluation and presenting with stable cardiac disease without hemodynamic instability. Demographic data for the enrolled 
subjects is presented in Table 1. The mean age of subjects with no prior surgery is $4.6 \mathrm{y}$ (range, $0.3-17 \mathrm{y}$ ), $4.7 \mathrm{y}$ (range, $0.4-15 \mathrm{y}$ ) for subjects with prior surgery and residual thymus, and $8.4 \mathrm{y}$ (range 1-18 y) for subjects with prior surgery and no residual thymus.
Thymectomy results in a decrease in TREC. TREC values were used as a parameter of thymic output to identify subjects in whom thymopoiesis has been affected. Among subjects with no visible thymic tissue, 6 of 11 had no detectable TREC (or values at the limit of detection) ( $p=0.0015$ by Fisher's exact

Table 1. Demographic information

\begin{tabular}{|c|c|c|c|c|}
\hline & Age $(y)$ & Cardiac diagnosis & Age at previous surgery & Other diagnosis \\
\hline \multicolumn{5}{|c|}{ No prior surgery $(n=26)$} \\
\hline 1 & 0.3 & Atrioventricular canal & & Heterotaxy syndrome \\
\hline 2 & 0.4 & Coactation of the aorta & & Lung cystic adenomatoid malformation \\
\hline 4 & 0.7 & Dilated cardiomyopathy & & \\
\hline 5 & 0.7 & Tetrology of Fallot & & Williams syndrome \\
\hline 6 & 0.9 & Tetrology of Fallot & & \\
\hline 9 & 1 & Atrioventricular canal & & \\
\hline 10 & 1.5 & Dilated cardiomyopathy & & \\
\hline 11 & 1.5 & Atrioventricular canal & & \\
\hline 12 & 1.5 & Ventricular septal defect & & Down syndrome \\
\hline 13 & 2 & Atrioventricular canal & & Down syndrome \\
\hline 14 & 2 & Ventricular septal defect and atrial septal defect & & Facial hemangiomas \\
\hline 19 & 4 & Atrial septal defect & & \\
\hline 20 & 7 & Atrial septal defect & & \\
\hline 21 & 10 & Ventricular septal defect and atrial septal defect & & \\
\hline 22 & 11 & Atrial septal defect & & Asthma \\
\hline 23 & 12.5 & Atrial septal defect & & \\
\hline 24 & 14 & Subaortic stenosis & & \\
\hline 25 & 14 & Atrial septal defect & & \\
\hline 26 & 17 & Atrial septal defect & & \\
\hline \multicolumn{5}{|c|}{ Prior surgery-residual thymus present $(n=18)$} \\
\hline 27 & 0.4 & Tetrology of Fallot & $1 \mathrm{wk}$ & \\
\hline 28 & 0.5 & Double-inlet left ventricle and pulmonic stenosis & $1 \mathrm{wk}$ & \\
\hline 29 & 0.6 & Tetrology of Fallot & $1 \mathrm{wk}$ & Protein $\mathrm{C}$ deficiency \\
\hline 39 & 5.5 & Coarctation of the aorta and subaortic membrane & $4.9 \mathrm{y}$ & \\
\hline 40 & 7 & Hypoplastic left heart syndrome & $4 \mathrm{~d}, 8 \mathrm{mo}$ & Asthma \\
\hline 41 & 8 & Aortic stenosis & $6 y$ & \\
\hline 42 & 12 & Subaortic stenosis & $4.5 \mathrm{y}$ & Diabetes (Type I) \\
\hline 43 & 14 & Tetrology of Fallot & $3.5 \mathrm{y}$ & \\
\hline 44 & 15 & Tricuspid atresia and pulmonic stenosis & $6 \mathrm{wk}, 8 \mathrm{wk}, 1 \mathrm{y}, 9 \mathrm{y}$ & Juvenile rheumatoid arthritis \\
\hline \multicolumn{5}{|c|}{ Prior surgery-no residual thymus present $(n=11)$} \\
\hline 45 & 1 & Ventricular septal defect & $1 \mathrm{mo}, 6 \mathrm{mo}$ & \\
\hline 46 & 1 & Pulmonary atresia & $2 \mathrm{wk}$ & \\
\hline 47 & 4 & Dilated cardiomyopathy & $13 \mathrm{mo}$ & Heart transplant \\
\hline 48 & 4.5 & Tricuspid atresia & $5 \mathrm{mo}$ & \\
\hline 49 & 4.5 & Double-outlet right ventricle with pulmonary atresia & $10 \mathrm{~d}, 8 \mathrm{mo}$ & \\
\hline 50 & 7 & Transposition of the Great Arteries and ventricular septal defect & $1 \mathrm{wk}, 5 \mathrm{mo}, 1.7 \mathrm{y}$ & \\
\hline 51 & 12 & Tetrology of Fallot & $4.3 \mathrm{y}$ & \\
\hline 52 & 13 & Tetrology of Fallot & $13 \mathrm{mo}$ & \\
\hline 53 & 13.5 & Aortic stenosis & $5.5 \mathrm{y}$ & \\
\hline 54 & 13.5 & Ventricular septal defect and pulmonary stenosis & $4 y$ & Heterotaxy syndrome \\
\hline 55 & 18 & Mitral stenosis and coarctation of the aorta & $4 \mathrm{mo}, 18 \mathrm{mo}, 6 \mathrm{y}$ & \\
\hline
\end{tabular}


test), consistent with previous studies offering evidence that the concentration of TREC in PBMC correlates with thymic mass (20). Similarly, in the two individuals who were reported to have "trace" amount of thymus tissue, TREC were also undetectable. TREC were significantly decreased in both groups of subjects who had undergone surgical procedures compared with those who had no prior surgery $(p<0.001)$ (Fig. 1). In individuals with no visible thymus, TREC concentrations were significantly lower compared with those with no previous surgery $(p<0.0001)$ and those with prior surgery but residual thymus $(p=0.027)$. Decreases in those without compared with those with anatomic thymus present after surgical procedures reflects a lack of thymus function rather than effect of surgery, such as activation-induced proliferation of $\mathrm{T}$ cells, or other factors such as blood loss. In the subjects with congenital heart disease but no prior surgery, TREC concentrations were similar to those obtained from normal subjects in other published studies (19).

Timing of TREC decrease is consistent with cessation of thymopoiesis. Previous data obtained by others have suggested that TREC in circulating PBMC are long-lived $(14,21)$. We examined the TREC concentration relative to age and time since surgery in subjects to investigate the timing of TREC reduction relative to childhood growth and to determine the amount of time necessary to detect changes in measures of thymopoiesis (Fig. 2). Decreases in TREC were apparent at an early age after thymectomy in infancy. Moreover, despite the age differences between groups, mixed effects modeling shows that TREC concentration was predicted only by the presence of thymic tissue and previous surgical procedures and not by the effects of age $(p<0.0001)$ (Fig. 2a). We speculate that detection of low TREC values soon after surgery may reflect effects of dilution (blood loss with surgery, effects of cardiopulmonary bypass) or T-cell proliferation. However, in specimens from athymic individuals several years after surgery, TREC concentrations were undetectable, or approximately $30-$ to 100 -fold lower than similar aged subjects with no prior

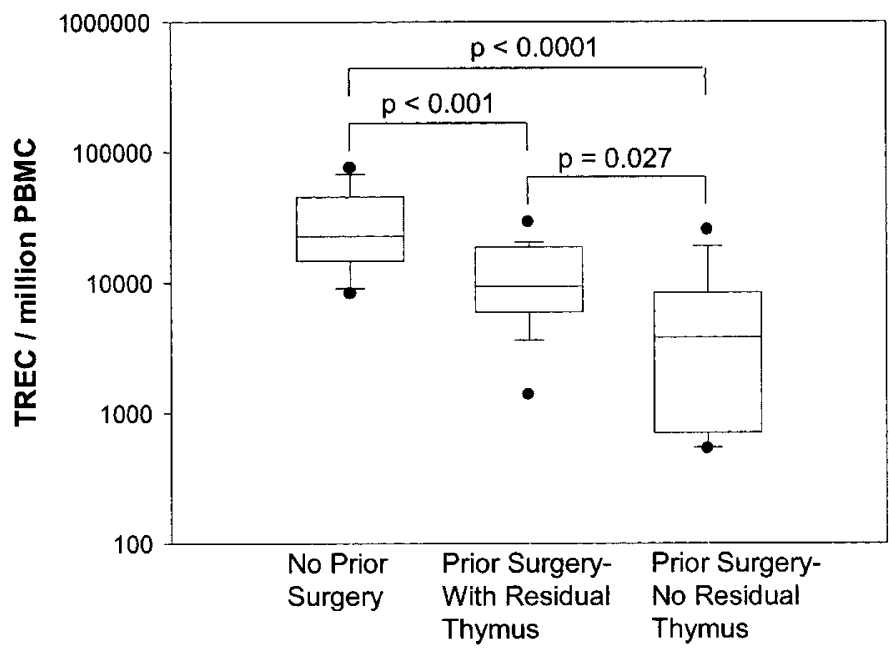

Figure 1. TREC in children with or without a history of cardiothoracic surgical procedures. TREC were measured using real-time PCR as described. Boxes are interquartile ranges and dots represent 5 th and 95th percentiles. Groups were compared using the Wilcoxon rank-sum test. a.

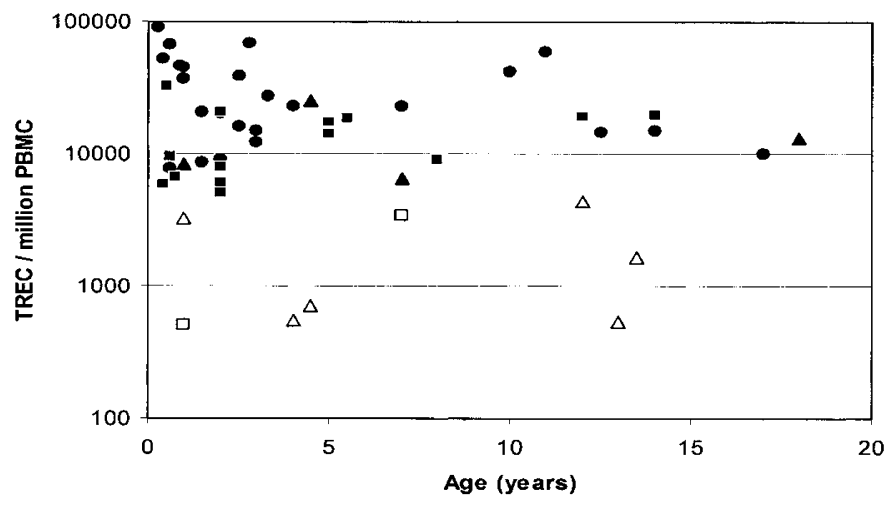

b.

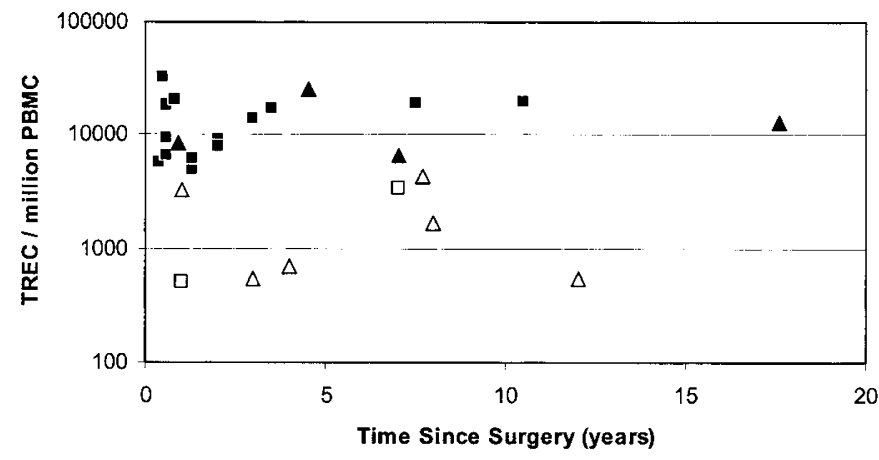

Figure 2. Changes in TREC number by age and time since surgery. TREC concentrations in subjects with no prior surgery (circles), or after previous surgery, with residual thymus (squares) or without residual thymus tissue (triangles) are plotted by age (a). Undetectable TREC are plotted at the limit of detection for each sample and are indicated by open figures. TREC concentrations for individuals who have a history of prior surgical procedure are plotted by time since surgery $(b)$. For individuals who have undergone multiple prior procedures, the time elapsed is since the first procedure was performed.

surgery, suggesting a lack of thymopoiesis. Further, these data suggest that, in some individuals, incidental thymectomy is complete and there is no regeneration of thymic tissue after surgery. When TREC are analyzed by time after surgery, evidence for long-term, and presumably permanent, loss of thymopoiesis is apparent in some subjects without residual thymus (Fig. 2b).

Thymectomy results in a long-term decrease in total lymphocyte number, $\mathrm{CD}^{+}, \mathrm{CD}^{+}$, and nä̈ve $\mathrm{CD}^{+}$lymphocytes. To investigate the effects of thymectomy on the populations of $\mathrm{T}$ cells found in peripheral blood, we determined the number and percentages of total lymphocytes, $\mathrm{CD} 8^{+} \mathrm{T}$ cells, $\mathrm{CD} 4^{+} \mathrm{T}$ cells, and naïve $\mathrm{CD} 4^{+} \mathrm{T}$ cells in subjects with congenital heart disease, including individuals with prior cardiothoracic surgical procedures (Fig. 3).

There were significant differences in the total lymphocyte numbers as well as in absolute $\mathrm{CD} 4^{+}$and $\mathrm{CD} 8^{+} \mathrm{T}$ cells and absolute naïve $\mathrm{CD} 4^{+} \mathrm{T}$-cell counts between the subjects who have had prior surgery (with or without thymectomy) and those with no prior surgical procedures in total lymphocyte number $(p=0.002, p=0.002, p=0.004$, and $p=0.001$, respec- 
tively). Total lymphocytes were decreased in children with a history of prior cardiothoracic surgery and residual thymic tissue compared with those with no previous surgical procedure $(p=0.047)$. Subjects with no residual thymus had a decrease in total lymphocyte number, and absolute $\mathrm{CD} 4^{+}$and $\mathrm{CD} 8^{+}$T-cell counts compared with those with prior surgery and residual thymic tissue $(p=0.012, p=0.036$, and $p=$ 0.008 , respectively). Children with residual thymus also had decreased CD4 and CD8 counts compared with children with no prior surgery ( $p=0.046$ and $p=0.036$, respectively). Both the absolute number and percent of $\mathrm{CD} 4{ }^{+} \mathrm{CD} 45 \mathrm{RA}^{+} \mathrm{CD} 2 \mathrm{~L}^{+}$ (or $\mathrm{CD} 4{ }^{+} \mathrm{CD} 45 \mathrm{RA}^{+} \mathrm{CD} 27^{+}$cryopreserved $\mathrm{PBMC}$ ) naïve $\mathrm{T}$ helper cells were decreased in individuals who had undergone thymectomy when compared with individuals with no history of prior surgical procedure $(p=0.002)$ and to subjects with a prior and surgery but retaining thymic tissue $(p=0.020)$. We found no significant effect of age alone by mixed effects analysis. We also did not find a significant effect of age at time of previous surgery.

Of note, $\mathrm{CD} 8^{+} \mathrm{T}$-cell number was only at the 5 th percentile $\left(200-300\right.$ cells $\left./ \mathrm{mm}^{3}\right)$ in most individuals after thymectomy (22). Populations of double-positive $\left(\mathrm{CD}^{+}{ }^{+} \mathrm{CD} 8^{+}\right) \mathrm{T}$ cells did not appear to be affected by either surgery or thymectomy, generally accounting for $\leq 1 \%$ of the total $\mathrm{CD}^{+}$cells.

In view of the T-cell lymphocytopenia, an additional analysis was performed to determine whether lower TREC concentration in subjects who underwent thymectomy were due to reductions in T-cell number. Consistent with the findings in Figure 1, the TREC concentration per million $\mathrm{T}$ cells was significantly reduced in subjects with prior surgery and no thymus compared with subjects with no prior surgery $(p=$ $0.0014)$ and those with prior surgery and residual thymus present $(p=0.030)$. Additionally, subjects with residual thymus after previous surgical procedures had lower TREC concentration in T cells compared with those who have had no prior surgery $(p=0.043)$.

\section{DISCUSSION}

Our data provide evidence that cardiothoracic surgery and thymectomy in early childhood rapidly produces significant and enduring changes in peripheral blood $\mathrm{T}$ lymphocyte number that are consistent with loss of ongoing thymopoiesis. Although absence of the thymus during fetal life is associated with a complete absence of T-cell development and profound immunodeficiency (as seen in the complete DiGeorge syndrome), the postnatal contribution of the thymus to immune development had, historically, been unclear. However, recent data have confirmed that in normal individuals there is an ongoing contribution of the thymus to the maintenance of the T-cell compartment throughout life into old age $(2,10,15,23-25)$.

Several studies have attempted to describe the changes that occur in humans as a result of thymectomy. Most published studies describing the effects of thymectomy have been conducted in individuals with MG $(14,21,26)$. In a small study of thymectomized adult MG patients who never used immunosuppressive medications, Storek et al. (21) found a trend
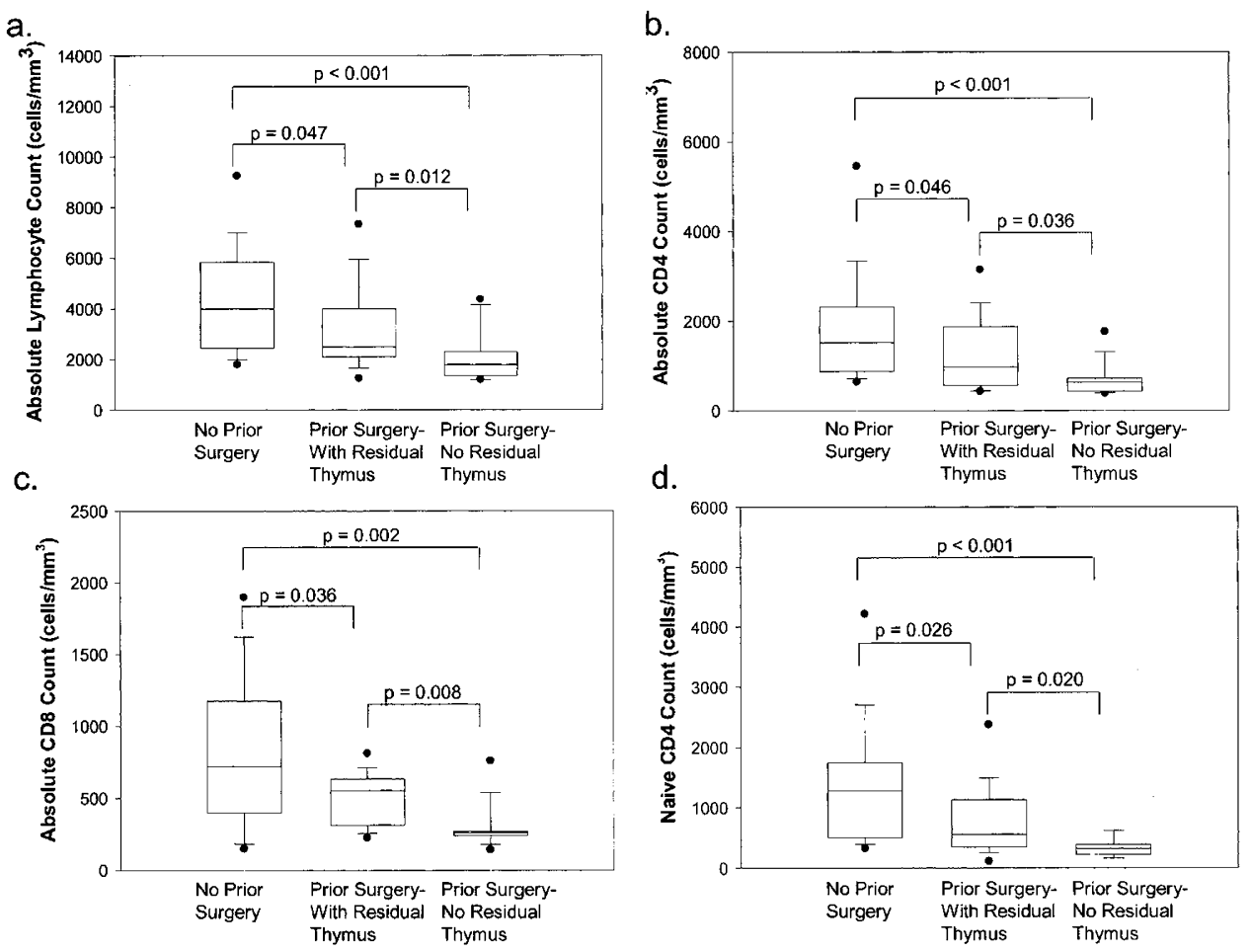

Figure 3. Peripheral lymphocyte counts and T-cell subsets. Absolute lymphocyte counts $(a)$, and T-cell subsets $\left(b: \mathrm{CD}^{+} / \mathrm{CD} 3^{+} ; c: \mathrm{CD} 8^{+} / \mathrm{CD} 3^{+} ; d\right.$ : $\mathrm{CD}^{+} / \mathrm{CD} 45 \mathrm{RA}^{+} / \mathrm{CD}_{2} 2 \mathrm{~L}^{+}$or $\mathrm{CD} 4^{+} / \mathrm{CD} 45 \mathrm{RA} / \mathrm{CD} 27^{+}$for cryopreserved specimens) for subjects with no previous surgery and those with or without residual thymus tissue after previous surgery. Boxes are interquartile ranges and dots represent 5 th and 95 th percentiles. Significance was calculated using the Wilcoxon rank-sum test. 
toward lower TREC in $\mathrm{CD}^{+}{ }^{+} \mathrm{T}$ cells and significantly lower TREC in $\mathrm{CD} 8^{+} \mathrm{T}$ cells compared with normal values. Because TREC levels were not zero (especially among CD4 cells) in their subjects, they speculated that thymectomy was incomplete, $\mathrm{T}$ cells may be generated de novo at extrathymic sites, or that TREC generated before thymectomy persist for decades. In contrast, TREC were undetectable in many of our subjects with no anatomic evidence of residual thymus. Thus, we find no evidence of extrathymic T-cell generation.

Extrapolation of published data describing the effects of thymectomy obtained in adult MG patients to a pediatric population presents a number of difficulties. Thymectomy performed before immunologic maturity may present a distinct condition with more pronounced effects on lymphocyte homeostasis and important implications for future neoantigen responses. In addition, somatic growth of infants may require significant peripheral expansion to maintain lymphocyte homeostasis and resultant dilution of lymphocyte subpopulations may occur within a short period of time after thymectomy. Therefore, both memory and naïve peripheral $\mathrm{T}$ cell clones are likely to have undergone significant peripheral expansion and may be unable to proliferate further upon exposure to antigen having reached replicative senescence $(27) . \mathrm{CD}^{+}$cells, in particular, may be affected by this phenomenon providing a possible explanation for the relatively low numbers of $\mathrm{CD} 8^{+} \mathrm{T}$ cells in our thymectomized subjects.

Data indicate that thymus mass and thymopoiesis have the potential to increase in response to decreased peripheral T-cell numbers $(20,28)$. In our study, individuals with no evidence of thymus tissue during visual inspection were more likely to have undetectable levels of TREC in the peripheral blood, whereas those with thymic tissue present had higher TREC levels, often near normal, indicating that partial removal or damage to the thymus may not be sufficient to completely abrogate its activity. Interestingly, two subjects with only "trace" amounts of thymus tissue had undetectable TREC levels consistent with the hypothesis that TREC correlate with thymus mass. TREC levels in our cohort of thymectomized children are 30- to 100-fold lower than those seen in similar aged individuals who were not thymectomized, suggesting that there are specific and substantial effects of thymectomy in infancy.

A new cohort of individuals with congenital cardiac disease is forming reflecting the growing practice of performing palliative and corrective surgery in infancy and early childhood. Younger individuals are more likely to undergo incidental thymectomy due to the small size of the infant thoracic cavity and higher complexity of surgeries performed at this age. Several previous studies have attempted to address changes in lymphocyte production that may result from incidental thymectomy performed during cardiothoracic surgical procedures in young children (4-7). Unfortunately, previous studies have involved limited immunophenotypic analysis of T cells and did not use recently developed methods to quantify thymic activity. Moreover, these investigators did not have information about the amount of residual thymus remaining after the surgical procedure. Ramos and colleagues (4) examined pediatric patients who had undergone incidental thymectomy dur- ing cardiac surgery. They discovered a difference in lymphocyte populations, specifically NK populations, suggesting a lack of normal lymphocyte differentiation in children who had undergone infant thymectomy, compared with those with thymectomy at an older age. In a 1998 report, Wells et al. (5) were able to identify differences in naïve CD4 cells between children without or without thymectomy 1 y after neonatal cardiac surgery. Although the investigators did find decreases in the number of naïve $\mathrm{CD} 4^{+} \mathrm{T}$ cells after thymectomy, they were unable to detect any difference in responses to tetanus toxoid after immunization. However, because tetanus vaccine normally requires little $\mathrm{T}$-cell help to mount a robust response, this assay may be insensitive to decreases in immune function resulting from thymectomy in infancy. Similarly, Eysteinsdottir et al. (6) examined lymphocyte subsets and T-cell responses in vitro, but only examined a small number of children including both thymectomized and nonthymectomized subjects in the study group and was unable to detect a decrease in T-cell activity compared with controls despite changes measured in lymphocyte populations. In another study, Gennery and colleagues (7) examined lymphocyte subsets in children who had undergone heart transplantation or had congenital cardiac disease and found that $\mathrm{CD} 8^{+} \mathrm{T}$-cell numbers were reduced compared with normal controls. In our study, we found greater effects in the $\mathrm{CD} 8^{+} \mathrm{T}$-cell subpopulation as well. In addition, our data suggest that, although the presence of congenital heart disease by itself does not have any significant effect on thymopoiesis or lymphocyte subpopulations, any thoracic surgical procedure, including those in which the thymus is spared, may produce long-term perturbations in peripheral T-cell populations.

Our data indicate that reduction or injury to functional thymus tissue during cardiothoracic surgical procedures in infants and young children can result in long-term reduction of new T-cell production as evidenced by a reduction in TREC number years later. Despite a reduction in thymic output of $\mathrm{T}$ cells and reduced peripheral lymphocytes, lymphocytes are maintained at minimal levels in thymectomized children by as yet undetermined mechanisms. These may include increased peripheral expansion or homeostatic mechanisms that result in perturbations in B or natural killer (NK) cells.

Although these data provide evidence that removing the thymus of young children affects peripheral T-cell populations in the long term, the impact on the risk of infectious disease or malignancy has not been evaluated. These observations suggest that the studies described thus far may underestimate the impact of early childhood thymectomy. Further investigation to assess the functional or clinical consequences of this practice would be valuable.

\section{REFERENCES}

1. Barrett DJ, Ammann AJ, Wara DW, Cowan MJ, Fisher TJ, Stiehm ER 1981 Clinical and immunologic spectrum of the DiGeorge syndrome. J Clin Lab Immunol 6:1-6

2. Jawad AF, McDonald-McGinn DM, Zackai E, Sullivan KE 2001 Immunologic features of chromosome 22q11.2 deletion syndrome (DiGeorge syndrome/ velocardiofacial syndrome). J Pediatr 139:715-723

3. Piliero LM, Sanford AN, McDonald-McGinn DM, Zackai EH, Sullivan KE 2004 T-cell homeostasis in humans with thymic hypoplasia due to chromosome $22 \mathrm{q} 11.2$ deletion syndrome. Blood 103:1020-1025

4. Ramos SB, Garcia AB, Viana SR, Voltarelli JC, Falcao RP 1996 Phenotypic and functional evaluation of natural killer cells in thymectomized children. Clin Immunol Immunopathol 81:277-281 
5. Wells WJ, Parkman R, Smogorzewska E, Barr M 1998 Neonatal thymectomy: does it effect immune function? J Thorac Cardiovasc Surg 115:1041-1046

6. Eysteinsdottir JH, Freysdottir J, Haraldsson A, Stefansdottir J, Skaftadottir I, Helgason H, Ogmundsdottir HM 2004 The influence of partial or total thymectomy during open heart surgery in infants on the immune function later in life. Clin Exp Immunol 136:349-355

7. Gennery AR, Barge D, Spickett GP, Cant AJ 2001 Lymphocyte subset populations in children with polysaccharide antibody deficiency following cardiac transplantation. $\mathrm{J}$ Clin Immunol 21:37-42

8. De Rosa SC, Herzenberg LA, Herzenberg LA, Roederer M 2001 11-color, 13parameter flow cytometry: identification of human naïve $\mathrm{T}$ cells by phenotype, function, and T-cell receptor diversity. Nat Med 7:245-248

9. Douek DC, Vescio RA, Betts MR, Brenchley JM, Hill BJ, Zhang L, Berenson JR, Collins RH, Koup RA 2000 Assessment of thymic output in adults after haematopoietic stem-cell transplantation and prediction of T-cell reconstitution. Lancet 355:1875-1881

10. Douek DC, McFarland RD, Keiser PH, Gage EA, Massey JM, Haynes BF, Polis MA Haase AT, Feinberg MB, Sullivan JL, Jamieson BD, Zack JA, Picker LJ, Koup RA 1998 Changes in thymic function with age and during the treatment of HIV infection. Nature 396:690-695

11. Kong F, Chen CH, Cooper MD 1998 Thymic function can be accurately monitored by the level of recent $\mathrm{T}$ cell emigrants in the circulation. Immunity 8:97-104

12. Steffens CM, Al-Harthi L, Shott S, Yogev R, Landay A 2000 Evaluation of thymopoiesis using $\mathrm{T}$ cell receptor excision circles (TRECs): differential correlation between adult and pediatric TRECs and naïve phenotypes. Clin Immunol 97:95-101

13. Ye P, Kirschner DE 2002 Reevaluation of $\mathrm{T}$ cell receptor excision circles as a measure of human recent thymic emigrants. J Immunol 169:4968-4979

14. Haynes BF, Hale LP, Weinhold KJ, Patel DD, Liao H, Bressler PB, Jones DM, Demarest JF, Gebhard-Mitchell K, Haase AT, Bartlett JA 1999 Analysis of the adult thymus in reconstitution of T lymphocytes in HIV-1 infection. J Clin Invest 103:453460

15. Haynes BF, Markert ML, Sempowski GD, Patel DD, Hale LP 2000 The role of the thymus in immune reconstitution in aging, bone marrow, transplantation, and HIV-1 infection. Annu Rev Immunol 18:529-560

16. Heitger A, Neu N, Kern H, Panzer-Grumayer ER, Greinix H, Nachbaur D, Niederwieser D, Fink FM 1997 Essential role of the thymus to reconstitute naive $\left(\mathrm{CD}_{\left.45 \mathrm{RA}^{+}\right)} \mathrm{T}\right.$-helper cells after human allogeneic bone marrow transplantation. Blood 90:850-857

17. Mackall CL, Hakim FT, Gress RE 1997 T-cell regeneration: all repertoires are not created equal. Immunol Today 18:245-251
18. Zhang L, Lewin SR, Markowitz M, Lin HH, Skulsky E, Karanicolas R, He Y, Jin X, Tuttleton S, Vesanen M, Spiegel H, Kost R, van Lunzen J, Stellbrink H, Wolinsky S, Borokowsky W, Palumbo P, Kostrikis LG, Ho DD 1999 Measuring recent thymic emigrants in blood of normal and HIV-1 infected individuals before and after effective therapy. J Exp Med 190:725-732

19. Pham T, Belzer M, Church JA, Kitchen C, Wilson CM, Douglas SD, Geng Y, Silva M, Mitchell RM, Krogstad P 2003 Assessment of thymic activity in human immunodeficiency virus-negative and -positive adolescents by real-time PCR quantitation of T-cell receptor rearrangement excision circles. Clin Diag Lab Immunol 10:323328

20. Vigano A, Vella S, Saresella M, Vanzulli A, Bricalli D, DiFabio S, Ferrante P, Andreotti M, Pirillo M, Dally LG, Clerici M, Principi N 2000 Early immune reconstitution after potent antiretroviral therapy in HIV-infected children correlates with the increase in thymus volume. AIDS 14:251-261

21. Storek J, Douek DC, Keesey JC, Boehmer L, Storer B, Maloney DG 2003 Low T cell receptor excision circle levels in patients thymectomized 25-54 years ago. Immunol Lett 89:91-92

22. Comans-Bitter WM, deGroot $\mathrm{R}$, van den Beemd R, Hop WC, Groeneveld K, Hooijkaas H, van Dongen JJ 1997 Immunophenotyping of blood lymphocytes in childhood. Reference values for lymphocyte subpopulations. J Pediatr 130:388-393

23. Jamieson BD, Douek DC, Killian S, Hultin LE, Scripture-Adams DD, Giorgi JV, Marelli D, Koup RA, Zack JA 1999 Generation of functional thymocytes in the human adult. Immunity 10:569-575

24. Poulin JF, Viswanathan MN, Harris JM, Komanduri KV, Wieder E, Ringuette N, Jenkins M, McCune JM, Sekaly RP 1999 Direct evidence for thymic function in adult humans. J Exp Med 190:479-486

25. Fry TJ, Mackall CL 2002 Current concepts of thymic ageing. Springer Semin Immunopathol 24:7-22

26. Sempowski GD, Thomasch JR, Gooding ME, Hale LP, Edwards LJ, Ciafaloni E, Sanders DB, Massey JM, Douek DC, Koup RA, Haynes BF 2001 Effect of thymectomy on human peripheral blood $\mathrm{T}$ cell pools in myasthenia gravis. $\mathrm{J}$ Immunol $166: 2808-2817$

27. Effros RB, Globerson A 2002 Hematopoietic cells and replicative senescence. Exp Gerontol 37:191-196

28. Napolitano LA, Grant RM, Deeks SG, Schmidt D, DeRosa SC, Herzenberg LA, Herndier BG, Andersson J, McCune JM 2001 Increased production of IL-7 accompanies HIV-1-mediated T-cell depletion: implications for T-cell homeostasis. Nat Med 7:73-79 